\title{
UV-Curable Adhesive as the Low-Cost Material of Choice for Microfluidic Forensic Applications
}

\author{
Ph. Wägli ${ }^{1}$, Ch. Berchtold ${ }^{2}$, A. Homsy ${ }^{1}$, P.D. van der Wal ${ }^{1}$, N.F. de Rooij ${ }^{1}$ \\ ${ }^{1}$ Ecole Polytechnique Fédérale de Lausanne, IMT SAMLAB, Rue Jaquet Droz 1, \\ 2000 Neuchâtel, Switzerland, philip.waegli@epfl.ch \\ ${ }^{2}$ ETH Zurich, D-CHAB LOC, Wolfgang-Pauli-Str. 10, 8093 Zürich, Switzerland
}

\begin{abstract}
There is a push towards disposable, polymer-based microfluidic devices for medical and forensic applications to reduce cost and cross contamination between different samples. Therefore, more and more polymer-based systems are developed and they replace the common systems made of silicon or glass.

But one of the main challenges of systems made of polymers is the adsorption/absorption of molecules. For microfluidic-based chemical sensors, it is essential that the analyte is not adsorbed on the walls of the microfluidic channels before detection.

Here we present a study of the adsorption of cocaine molecules by low-cost polymer microfluidic devices. We manufactured the systems by a simple and low-cost rapid-prototyping method using a UV-curable adhesive. Remarkable low adsorption values (up to $100 \%$ recovery rate) were found by liquid chromatography - mass spectroscopy (LC-MS) measurements for this potential polymer for forensic applications.
\end{abstract}

Key words: Adsorption of cocaine, microfluidic devices, UV-curable adhesive, liquid chromatographymass spectroscopy

\section{Introduction \& Background}

In our project, we are developing an integrated optical microsystem in the mid-infrared range to detect cocaine in human saliva [1]. To ensure a high signal-to-noise ratio, the analyte needs to be transferred from saliva to an IR-transparent organic solvent (tetrachloroethylene) by means of liquid-liquid extraction so that it can be analysed on chip using attenuated total refelction infrared (ATR-IR) spectroscopy. This liquid-liquid extraction is performed by diffusion of the analyte in a microfluidic $\mathrm{H}$-filter [2] where two immiscible fluids flow in parallel.

Since the late 90s, polydimethylsiloxane (PDMS) has become one of the most used and investigated materials in low-cost microfluidic systems [3]. However, PDMS swells upon contact with the organic solvents used for the cocaine extraction [4]. Further, PDMS is known as a good adsorbent of cocaine. Because of this adsorption property, PDMS is even commonly used for solid-phase micro-extraction (SPME) of cocaine $[5,6]$.
For our project we are looking for a low-cost polymeric material with low absorption of organic solvents (no swelling) and also low adsorption of analytes. In contrast to PDMS, the thiolene-based UV-curable adhesive we use is chemically compatible with many different organic solvents [7]. Moreover, it shows low adsorption of proteins (interleukins) from blood [8]. In our study of molecule adsorption, we observed a remarkably high recovery rate of the analyte cocaine.

In addition to these properties, this low-cost, commercially available, UV-curable adhesive has other advantages in microfluidic forensic applications, such as low auto-fluorescence, biocompatibility, high elastic modulus ( 1GPa) and impermeability to air and water vapor [9$11]$.

\section{Experimental}

We made microfluidic chips by means of rapid prototyping using Norland Optical Adhesives (NOA81, Norland Products Inc., USA) [7]. First, in the cleanroom, a layer of SU-8 (MicroChem Corp, Newton, MA, USA) on a glass substrate 
was structured by common photolithography in the shape of the meander microfluidic channel. The design was then replicated in

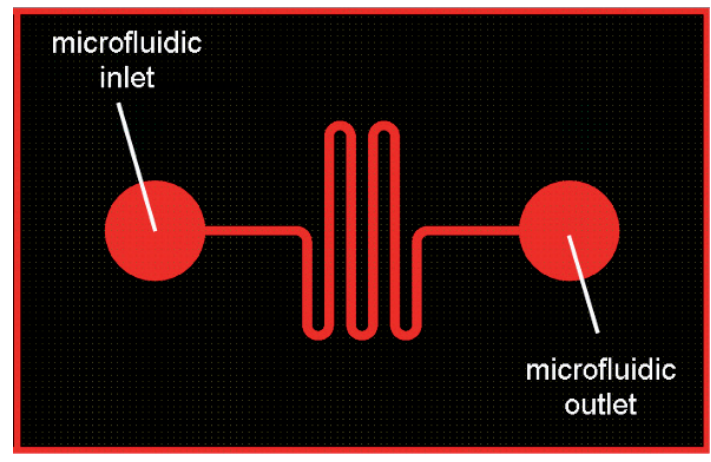

Fig. 1: Design of the meander microfluidic channel of uniform width $(150 \mu \mathrm{m})$.

polydimethylsiloxane (PDMS). The UV-curable adhesive was then molded and cured on this PDMS master. In parallel also a thin film of adhesive was cured, sandwiched between two flat PDMS layers, and then mounted on a microscope glass slide as substrate. The casted part containing the open microfluidic channel and the thin film were then bonded together by oxygen plasma to form a closed, all-polymer microfluidic channel.

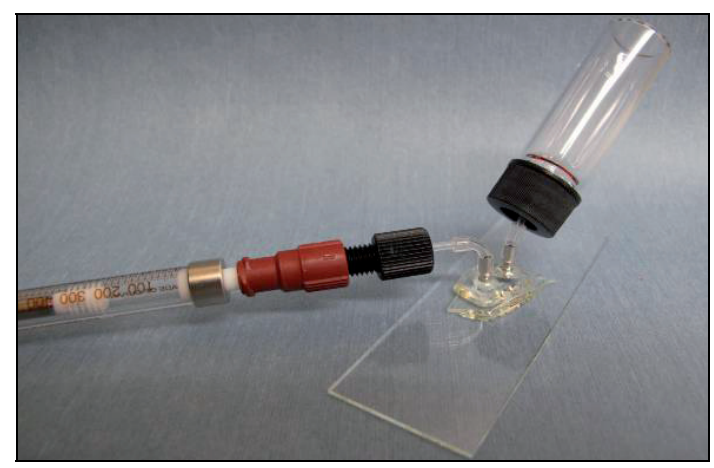

Fig. 2: Image of the adsorption tests chip: inlet connected to syringe, output connected to reservoir.

The microfluidic design is shown in Fig. 1 and consists of a simple serpentine microfluidic channel $(150 \mu \mathrm{m}$ wide and $40 \mu \mathrm{m}$ deep). The total surface of the UV-curable adhesive exposed to the liquid, including inlet and outlet ports, was $12.65 \mathrm{~mm}^{2}$.

Different cocaine concentrations dissolved in saliva and tetrachloroethylene were flowed through the microfluidic chips at a flow rate of $10 \mu \mathrm{l} / \mathrm{min}$ (see Fig. 2). Saliva was collected from healthy adult volunteers ( $\mathrm{pH} 6.8 \pm 0.2)$, filtered through a commercially available PES $0.22 \mu \mathrm{m}$ syringe filter (volume reduction by a factor of around 2) and spiked with cocaine (purity higher than 98\%, Lipomed AG, Switzerland). The cocaine was purchased with the permission of the cantonal drug administration of Neuchatel. The same concentrations were also pumped through a reference system consisting only of the tubing (of equal length) as

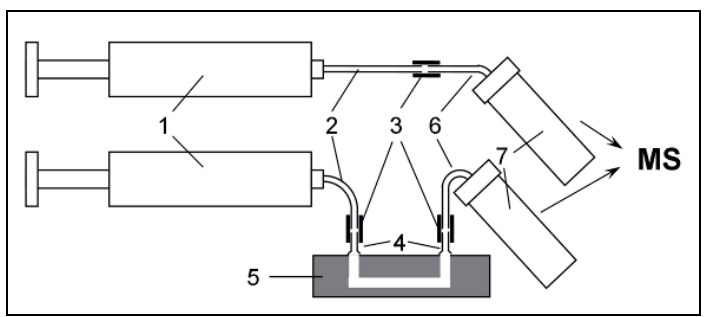

Fig. 3: Schematic of the adsorption test setup: 1) glass syringe, 2) Teflon $\AA$ tube $(2.5 \mathrm{~cm}), 3)$ Viton ${ }^{\circledR}$ connector, 4) metallic socket, 5) polymer microfluidic chip, 6) Teflon ${ }^{\circledR}$ tube $(1.5 \mathrm{~cm})$, 7) glass reservoir used for the transfer to mass spectroscopy (MS).

presented schematically in Fig. 3. The cocaine concentration (c) of the samples flowed through the polymer microfluidic chip and the reference system was determined by liquid chromatography mass - spectrometry (LC-MS) and then used to calculate the recovery rate $(r)$.

$r=\frac{c_{\text {microfluidicsystem }}}{c_{\text {referencesytem }}} \cdot 100 \%$

A new detection routine was developed to analyze cocaine concentrations in tetrachloroethylene by mass spectroscopy

Tab. 1: Mean recovery rate, standard deviation (SD), and coefficient of variation (CV) given in \% for the solvents saliva and tetrachloroethylene as function of different cocaine concentrations.

\begin{tabular}{|c|c|c|c|c|c|c|}
\cline { 2 - 7 } \multicolumn{1}{c|}{} & \multicolumn{3}{c|}{ human saliva } & \multicolumn{3}{c|}{ tetrachloroethylene } \\
\hline cocaine concentration & recovery rate & SD & CV & recovery rate & SD & CV \\
\hline $20 \mathrm{ng} / \mathrm{ml}$ & $\mathbf{8 5}$ & 21 & 24 & $\mathbf{8 6}$ & 11 & 13 \\
\hline $2 \mu \mathrm{g} / \mathrm{ml}$ & $\mathbf{9 3}$ & 4 & 5 & $\mathbf{9 1}$ & 12 & 14 \\
\hline $20 \mu \mathrm{g} / \mathrm{ml}$ & $\mathbf{9 2}$ & 13 & 14 & $\mathbf{8 9}$ & 16 & 18 \\
\hline $400 \mathrm{\mu g} / \mathrm{ml}$ & $\mathbf{1 0 1}$ & 8 & 8 & $\mathbf{1 0 0}$ & 2 & 2 \\
\hline
\end{tabular}


(LCQ-DECA XP, Thermo Finnigan). For saliva based samples the water was evaporated and replaced by tetrachloroethylene.

\section{Results \& Discussion}

A very high recovery rate of the cocaine was observed in the aqueous (saliva) and organic (tetrachloroethylene) solvent. Except for the lowest cocaine concentration $(20 \mathrm{ng} / \mathrm{ml})$, the saliva samples showed recovery rates higher than $92 \%$ (see Tab. 1). Low values of the standard deviation confirm stable recovery rates.

We observed low adsorption at low flow rates for microfluidic systems. Theoretically, we expect even less adsorption at higher flow rates.

The whole adsorption test was repeated with polymer microfluidic chips aged for 3 month. No significant difference between fresh and old chips was measured.

\section{Conclusion}

By using mass spectroscopy a very accurate detection method was applied in this study to determine the cocaine concentrations and high recovery rates for a wide range of concentrations in saliva and tetrachloroethylene was observed.

This low cocaine adsorption characteristic and other material properties such as low autofluorescence, biocompatibility, good chemical compatibility with organic solvents, high elastic modulus and impermeability to air and water vapour make this UV-curable adhesive a promising material for low-cost microfluidic devices for medical and forensic applications, such as drug screening and other sensing purposes.

\section{Acknowledgements}

This project is scientifically evaluated by the Swiss National Science Foundation (SNSF), financed by the Swiss Confederation and funded by Nano-Tera.ch.

\section{References}

[1] IrSens Project description available at: www.nano-tera.ch/projects/80.php

[2] P. Yager, T. Edwards, E. Fu, K. Helton, K. Nelson, M.R. Tam, B.H. Weigl, Nature 442(7101), 412-418 (2006); doi: 10.1038 /nature05064

[3] D.C. Duffy, J.C. McDonald, O.J.A. Schueller, G.M. Whitesides, Analytical Chemistry 70(23), 4974-4984 (1998); doi: 10.1021/ac980656z

[4] J.N. Lee, C. Park, G.M. Whitesides, Analytical Chemistry 75(3), 6544-6554 (2003); doi: 10.1021/ac0346712

[5] H. Lai, I. Corbin J.R. Almirall, Analytical Bioanalytical Chemistry 392(1-2), 105-113 (2008); doi: 10.1016/j.jcis.2005.06.037

[6] J. Pawliszyn, ed., Chemical Industry Press of China, 406 pp (2009); ISBN: 978-7-122-04701-4

[7] Ph. Wägli, A. Homsy, N.F. de Rooij, Sensors and Actuators B: Chemical 156(2), 994-1001 (2011): doi: 10.1016/j.snb.2011.02.005

[8] A. Homsy, P. van der Wal, W. Doll, R. Schaller, S. Korsatko, M. Ratzer, M. Ellmerer, T.R. Pieber, A. Nicol, N.F. de Rooij, Biomicrofluidics (2011); doi: $10.1063 / 1.3672188$

[9] Ph. Wägli, B.Y. Guélat, A. Homsy, N.F. de Rooij, Proc. of mTAS Conference, 1937-1939 (2010).

[10] D. Bartolo, G. Degre, P. Nghe, V. Studer, Lab on a Chip 8(2), 274-279 (2008); doi: 10.1039/B712368j

[11] M. Morel, D. Bartolo, J.-C. Galas, M. Dahan, V. Studer, Lab on a Chip 9(7), 1011-1013 (2009); doi: 10.1039/B819090A 